\title{
Mergers after cartels: How markets react to cartel breakdown $^{12}$
}

\author{
Stephen Davies ${ }^{3}$, Peter L. Ormosi ${ }^{4}$, and Martin Graffenberger ${ }^{5}$
}

June 27, 2015

${ }^{1}$ Forthcoming in The Journal of Law and Economics 58 (Nov)

${ }^{2}$ We are grateful for comments from participants of seminars at the Office of Fair Trading, the Economics seminar series of Université Paris X, and the Centre for Competition Policy, UEA. Thanks are also due to Leslie Marx, Matthew Olczak, and Chris Wilson, the editor of this journal and an anonymous referee. The usual disclaimer applies. The support of the Economic and Social Research Council and the ESRC Centre for Competition Policy is gratefully acknowledged.

${ }^{3}$ School of Economics and ESRC Centre for Competition Policy, University of East Anglia, Norwich Research Park, NR4 7TJ, Norwich, United Kingdom, email: s.w.davies@uea.ac.uk

${ }^{4}$ Norwich Business School and ESRC Centre for Competition Policy, University of East Anglia, Norwich Research Park, NR4 7TJ, Norwich, United Kingdom, email: p.ormosi@uea.ac.uk

${ }^{5}$ ESRC Centre for Competition Policy, University of East Anglia, Norwich Research Park, NR4 7TJ, Norwich, United Kingdom 


\begin{abstract}
This paper examines whether cartel breakdown provokes a period of intensive merger activity amongst the former cartelists, designed to re-establish tacit collusion. Using a novel application of recurrent event survival analysis for a pooled sample of 84 European cartels, it finds that mergers are indeed more frequent post-cartel breakdown, especially in markets which are less concentrated. However, it cautions against merely assuming that these mergers are motivated by coordinated effects - alternatively, they may be the consequence of market restructuring, necessitated by more intense competition post-cartel. Further disaggregated analysis of the individual mergers show that on average these mergers are profitable for the acquiring company, and that the tacit collusion motive is likely to be at work for a large minority of the mergers.
\end{abstract}

Keywords: collusion, mergers, long-term effect, recurrent events, survival analysis

JEL Classification codes: C41, L10, L41 


\section{Introduction}

Anti-cartel enforcement is widely heralded as the single most important part of antitrust policy. For this reason it is somewhat surprising that there have been relatively few studies analysing how markets react to the elimination of cartels. This paper takes a dynamic approach in examining what happens in markets in the years after a competition authority (CA) has successfully prosecuted a cartel. Do markets revert to competitive behaviour or do firms find alternative ways of reinstating collusive equilibria (short of cartelisation) in the longer run?

The most common approach for assessing the impact of cartel policy has been to examine post-cartel prices, and a common method for quantifying overcharge is to compare post-cartel against within-cartel period prices. While this approach can be illuminating, suitable price data are often unavailable, especially over anything more than the short-term. Here instead we turn to a more indirect approach in order to use types of longer-run data which are more readily available, namely on quantity and market structure. This follows the insight of seminal works in the early 1990s by Sutton (1991), and Bresnahan and Reiss (1991) who showed, using very different analytical approaches, how information about market shares and structure can be informative about the competitive process, even without information on price and profits.

In this case, the market structure changes are often typically achieved by mergers. We have collected data on mergers, acquisitions and joint ventures (hereafter referred to under the catch-all 'merger') between firms involved in those cartels for which the European Commission (EC) issued decision documents between 1990 and 2012. We pose two questions. First, was there more intense merger activity amongst the former cartelists in the years immediately following breakdown? Second, is there evidence that these mergers were motivated by coordinated effects?

The methodological novelty of the paper lies in our approach to the first of these questions. We rule out a standard difference-in-differences (DiD) approach for vari-

ous reasons (most importantly because the data are censored and there is a lack of appropriate counterfactual). Instead, we apply a recurrent event survival analysis, 
which is ideal for applications such as this. Moreover, the characteristics of hazard analysis allow us to think of the time period immediately following cartel breakdown as the treatment group, and the later years as the control. Therefore we are testing whether the hazard of a merger is highest following cartel breakdown against the counterfactual of merger hazard that is constant over time periods. Unlike in standard survival analysis, here 'failure' is recurrent (the typical market has more than one subsequent merger) and this requires use of less standard recurrent failure survival models. We show how our main hypothesis can be tested directly for the pooled sample by a straightforward test on the curvature of the Weibull distribution.

Our results confirm that there is indeed evidence of more intensive post-breakdown merger activity. This is most pronounced for (i) the subset of cartels which were detected only after they had already broken down, and (ii) those in relatively less concentrated markets. Our explanation for (i) is that breakdown due to 'natural causes' is indicative of a cartel which has become internally unstable. With formal collusion unsustainable, this increases the appeal of tacit collusion, but this necessitates mergers in order to achieve a structure conducive to tacit collusion. On (ii) there are two alternative explanations: in industries which are already more concentrated, mergers may be unnecessary for collusion; but alternatively, firms may be deterred from merging because they anticipate CA intervention.

In order to assess how far mergers after cartel are explicable in terms of the collusive motive, we introduce two screens using disaggregated data on the individual mergers. These are designed to identify how frequently the mergers would lead to market structures usually viewed by the CA as necessary for coordinated effects (because they enhance symmetry amongst leading firms); and how the financial markets react to the mergers by marking up the values of both the acquiring firm and its rivals (conventionally interpreted in the event study literature as indicative of coordinated effects). Taken together, these screens suggest that in at least a significant minority of cases, post-cartel mergers may have had the effect of dampening competition through tacit collusion.

This study belongs to a wider tradition in which mergers are viewed as triggered by some industry shock. Reviewing the relevant literature Mitchell and Mulherin 
(1996) identifies deregulation, oil price shocks, foreign competition, or and financial innovations as a triggering event. In our case, the shock that may lead to increased merger activity is cartel breakdown. More specifically, the literature on mergers subsequent to cartel can be traced back, through Bittlingmayer (1985) and Mueller (1996), to the first great merger wave in the US at the beginning of the 20th century, following the Sherman Act prohibition of cartels. Something very similar was observed in the UK following the Restrictive Trade Practices Act in the 1950s. Symeonides' (2002) extensive research on this provides more indirect evidence that prohibition of cartels preceded a major restructuring in parts of the UK economy. The main implication for policy makers was highlighted by Evenett and Levenstein and Suslow (2001, pp.1245): "(V)igilance should not end with a cartels' punishment, as former price-fixers often try to effectively restore the status quo ante by merging or by taking other steps that lessen competitive pressures and raise prices."

More recently, three studies have returned to the topic, but at a more micro level within a jurisdiction (the EU) in which cartels are already illegal, and where the event is not some major natural experiment but rather the busting of individual cartels. Kumar et al. (2013) show that for $45 \%$ of cartels reported by the EC between 2001-2010, there were mergers between the former cartelists in following years, and that this was twice as likely in markets where buyers were fragmented. They use this to motivate their theoretical modelling of the choice between collusion and merger when faced with buyer resistance. In a subsequent paper by Marx and Zhou (2014) they make further use of their sample, and test how various policy changes, such as the introduction of leniency programmes, affected the intensity of post-cartel merger activity. Hüschelrath and Smuda (2013) also employ a sample of EC cartels. But in their case, the merger data do not relate directly to the cartelists, but rather the amount of aggregate worldwide/EEA merger activity in the industries to which the cartel markets belong. Pooling the industries, they calculate that merger activity was (up to) $83 \%$ higher in the 3 years after, than in the 3 years before cartel detection.

Our own study is based on a similar sample of EU cartels, and also examines the proposition that merger is a second best which is only pursued once the first best (cartel) is no longer possible. However, we differ from these papers in a number of 
respects. Kumar et al's empirical objective is limited to motivating their theoretical model, establishing whether merger after cartel varies with buyer resistance - they provide no evidence on whether mergers were more prevalent after detection than before. Unlike us, Marx and Zhou focus on the effect of policy changes on the behaviour of cartel members. Our focus is on establishing how the market evolved after cartel breakdown and examining what motivated post-cartel mergers. The primary objective of Hüschelrath and Smuda is closer to ours, but their empirical analysis is too aggregate and casual to justify the conclusions they draw. Their merger data relate not to the cartelists themselves, but to all firms worldwide in the NACE 3 or 4 digit industries to which the cartel markets belong. ${ }^{1}$ So for example, they employ aggregate data on mergers by all firms worldwide in the "manufacture of pharmaceutical preparations" to proxy the cartel markets in Europe in finely disaggregated markets such as Citric Acid or Vitamins. Moreover, all data are pooled across all industries/cartels, there are no controls for mergers in industries in which there were no cartels, and their empirical analysis is confined to simple comparisons of two aggregate figures, before and after, without any tests of statistical significance. Our study is less aggregate, and relates to subsequent mergers between only the former cartelists, and addresses head-on the methodological problem of how best to represent the counterfactual.

Section 2 reviews the conventional argument that post-cartel breakdown mergers are necessarily driven by coordinated effect motives. It suggests various qualifications and these constitute the key hypotheses of the paper. Section 3 describes the data and presents some opening descriptive statistics. Section 4 presents the survival analysis, and section 5 looks for evidence of coordinated effects using analysis of market shares and the reactions of the financial markets. Section 6 concludes.

\footnotetext{
${ }^{1} \mathrm{NACE}$ is a statistical classification of economic activities in the European Union. For the list of codes: http://ec.europa.eu/competition/mergers/cases/index/nace_all.html
} 


\section{The anti-competitive explanation revisited}

The theme underlying nearly all the literature described above is that mergers after cartel breakdown are designed to re-establish collusion, albeit in a tacit form (coordinated effects). ${ }^{2}$

\subsection{The conventional coordinated effect argument}

While this hypothesis is often not fully articulated in the literature, it appears to be based on the following revealed preference type of argument.

In principle, firms in any market choose between competing and colluding. In turn, collusion might take the form of hard-core cartel, or it might be softer and tacit. However, in order to achieve and sustain soft collusion, market structure must be right, and this may require mergers between some of the firms. Of course, the choice may be constrained by the basic demand, cost, and entry conditions of the market, and the presence of the CA may deter either cartel formation and/or anti-competitive mergers.

Now, in the case of a market previously but no longer cartelised, collusion was clearly feasible, and firms had revealed a preference for formal over tacit collusion. But with the cartel option now removed, firms turn to the second best - tacit collusion. Thus the revealed preference argument has two steps:

a) The cartel solution dominates soft competition via merger. Were this not so, firms would have opted for mergers in place of a cartel in the first place.

b) With the cartel option removed, firms will attempt to reinstate collusion, and this requires restructuring through merger.

\footnotetext{
${ }^{2}$ In addition to the literature discussed above, see Cosnita-Langlais and Tropeano (2013) who model the choice of two firms between forming a cartel and merging in order to facilitate subsequent collusion when faced with a CA which optimises its policy mix between cartel enforcement and merger control.
} 


\subsection{Qualifications}

Without rejecting this line of reasoning, we caution against assuming that mergers after cartel breakdown necessarily always imply tacit collusion, or, indeed, that tacit collusion necessarily requires merger. Rather, three important qualifications should be recognised in empirical testing.

\subsubsection{Merger may not always be necessary}

With the cartel option no longer open, mergers may not always be necessary in order to achieve the second best of tacit collusion, therefore part (b) need not always apply. After all, much of the conventional theory of collusion can be applied equally to tacit collusion and cartels. For example, the basic predictions of the repeated game - that collusion is more likely the fewer is the number of firms and the more symmetric they are - are invoked in both the literatures on cartels and coordinated effects mergers.

In these cases, given that the cartel was chosen but is now busted, the second best tacit collusion may be profitable and sustainable for the firms, even without merger. Harrington (2004) refers to a concept of 'residual collusion', where a busted cartel is followed by tacit collusion. Connor (2001) uses the same argument to explain what happened in the aftermath of the Lysine cartel. A study by Kovacic et al. (2007) on prices in the post-breakdown period for different types of vitamins implies a simple switch to tacit collusion in some cases. They find that vitamin products with two conspirators continue as if the explicit conspiracy never stopped, while products with three or four conspirators return to pre-conspiracy pricing, or lower. This is also confirmed in an experimental setting by Fonseca and Normann (2012) , who find that, after formal communication is no longer possible, 'firms' carry on successfully colluding in small numbers cases.

If this previous communication is sufficient to sustain tacit collusion, then we should expect at least some markets to still display collusive outcomes post-cartel even without merger. This would be more likely, the more concentrated the market already is, and the more symmetric are the leading firms. 


\subsubsection{Cartels may no longer be preferred at time of breakdown}

While part (a) of the argument must have applied at the time of the cartel's formation, it may no longer be true at the date of its breakdown. In particular, if the cartel has already broken down before detection by the CA (we refer to this as having died a 'natural death'), this suggests that collusion was no longer sustainable - even with communication - and we can no longer infer that cartel is preferred to merger at the time of breakdown. But by the same token, if the cartel is unstable, so too will be tacit collusion - without merger. In other words, we would expect mergers after CA intervention to be even more prevalent in cases where the cartel has already broken down.

\subsubsection{An alternative 'efficiency' explanation}

Neither of the above qualifications questions the basic hypothesis that the mergers, where they occur, are motivated by coordination effects. However, there is a more benevolent explanation for merger after cartel breakdown - one which seems to have been largely ignored in this specific literature.

Suppose that the cartel breakdown has the desired objective from the CA's perspective. It leads to a change in prevailing conduct from collusion to competition; as

price falls, marginal firms exit, and some of the exit is via acquisition by other previous members of the cartel. For example in a free entry model, replacing collusion with, say, Cournot or Bertrand competition will lead to a reduced number of firms (Sutton 1991, section 2.2, pp.28-37), and in an asymmetric market the ones that exit are the least efficient firms (the smallest in Cournot). If so, restructuring by merger may be a socially efficient market response to the CA intervention.

\subsection{Testable hypotheses}

This leads to the following testable hypotheses:

H1 Cartel breakdown is followed by higher than normal merger activity in the years immediately after breakdown. 
Moreover, when a cartel breaks down naturally, this signals a market structure which is no longer sufficient to sustain collusion, even with the benefit of communication. If so, it is even less likely that tacit collusion can be sustained with that structure, and restructuring through merger is particularly necessary in these cases. So:

H1a H1 will be especially pronounced for cartels having died a natural death.

On the other hand,

H2 Increased merger activity will be lower in concentrated markets.

This would follow if markets are already sufficiently concentrated at breakdown to sustain subsequent tacit collusion without further merger. But equally, firms may be deterred by the fear of $\mathrm{CA}$ intervention from proposing mergers in already concentrated markets (especially when it is known that they were previously cartelised).

\subsection{Screens for coordinated effects}

Given that these hypotheses, even if supported by the data, are equally explicable in terms of the tacit collusion and efficiency explanations, this leaves open the obvious question of how we might distinguish the two. Detailed case studies of behaviour pre- and post-cartel in individual markets is one route, but our preferred approach here is to take the sample as a whole and apply the following two 'screens' using data which are readily at hand.

1. Structural Screen: how frequently do the mergers lead to market structures which would normally alert the CA to the possibility of coordinated effects?

2. Expected Profitability Screen: how frequently do financial markets react in a way consistent with expected coordinated effects (with beneficial effects for both the acquirer and its rivals)? 


\section{$3 \quad$ Data and descriptive statistics}

The major source of the data is the decision documents published by the European Commission (EC) since 1990. ${ }^{3}$ The usable sample is 84 cartels that were detected between 1984 and 2009. 36 of them (42\%) had broken down before they were detected. On average, the cartels had 7 members, lasted for 8 years, and covered $84 \%$ of their markets. Most involved agreements on price, but market sharing was also very common. A third of the cartels had an identifiable ringleader.

The cartels involved a total of 593 firms at the dates of breakdown. Data was collected on all relevant transactions - mergers, acquisitions and joint ventures - between these former cartelists, thus, this deliberately excludes mergers or acquisitions of firms who were not previously within the same cartel. ${ }^{5}$ We included all mergers after the date of breakdown, rather than the date of detection. ${ }^{6}$ The sources were: (i) companies' websites, in particular annual reports, press releases, investor information, company timelines/histories, and so on; (ii) merger decisions documents published by the European Commission; ${ }^{7}$ (iii) National Competition Authorities (CA); and (iv) business and financial websites (for example Bloomberg).

In almost exactly half (41) of the cartels, the breakdown was followed by one or more mergers between previous cartelists (Table A2). There were 128 qualifying transactions, ${ }^{8}$ (on average 3 per cartel, but the distribution is highly skewed, with 19 transactions between cartelists in one case). The majority of transactions were

\footnotetext{
${ }^{3}$ The data are summarised in Tables A1 and A2 in the Online Appendix.

${ }^{4}$ The published report typically lags the date of detection by one or more years. In assembling the sample, we consolidated two decision documents which cover the rubber market, and a number of reports relating to International Container Shipping cartels. In some other cases (notably vitamins) a single decision document relates to more than one cartel, but since these are always in very closely related submarkets, we count them here as a single case.

${ }^{5}$ 'Relevant' is defined by the 3 or 4 digit NACE industry identified by the Commission in its decision document. In fact, many of the cartel markets are much more finely defined than even the 4 digit level. In that case, the cartel market belongs to the 3 or 4 digit industry identified by the $\mathrm{EC}$, but is only a part of that industry.

${ }^{6}$ These two characteristics of our sample (mergers between former cartelists, after the cartel breakdown) make it different from the samples used by other studies in the literature.

${ }^{7}$ http://ec.europa.eu/competition/mergers/cases/

${ }^{8}$ The dataset assembled by Kumar et.al (2013) is a subset of 55 of the cartels in our sample. They identify mergers in 25 cases: $45 \%$ of their sample. We find mergers in $49 \%$ of our sample.
} 
mergers, but 20 per cent were joint ventures. ${ }^{9} 43$ percent of all transactions were funded by combinations of cash, share or debt; the remaining were either solely cash, share or debt funded. ${ }^{10}$

We also collected data on the market shares of the individual cartelists using sources such as (i) cartel and merger decision documents published by the EC and national CAs (ii) companies' annual reports (iii) reports and information issued by relevant trade/industry associations and market intelligence firms/platforms (iv) business and financial websites and so on. ${ }^{11}$ This proved possible for 64 of the cartels. ${ }^{12}$ These data allow us to calculate the HHI index at the time of breakdown for each market, and to estimate the impacts of 72 of the mergers on market structure for the structural screen. ${ }^{13}$

\footnotetext{
${ }^{9}$ We found no obvious statistically significant differences between mergers \& JVs for any of the cartel caracteristics.

${ }^{10}$ Overall, we find that cash was the most frequently used funding option in our sample, debt as a funding option was applied in nearly half of the cases and approximately one third of the transactions were, to some extent, funded by the exchange of equity.

${ }^{11}$ The EC does not routinely report exact market share data in its decision documents, but it is possible to infer individual market shares for most cartels, if sometimes only approximately. Firms' shares are often reported as ranges, for example 10-20\%; in such cases we typically employ the midpoints, subject to moderation where other information is available on an ad hoc basis.

${ }^{12}$ In addition to the mergers for which we have no market share data, we also exclude 29 mergers for which closer investigation reveals that there was no direct impact on market shares in the cartel markets as precisely defined by the EC. This reflects a feature of how the data for the merger database was collected - we identified all mergers between previous members of a given cartel, where the merger occurred within the NACE industry to which the cartel market belonged. However, often the cartel market, as identified by EC, was more disaggregated than the NACE industry to which it belongs. Thus these 29 mergers (or joint ventures/transfers of assets) were confined to the firms' activities in another country/product line than the specific market in which the cartel was detected. Although these are excluded for present purposes, they merit attention in future research - on the possibility that the EC may have defined the cartel's product market or geographic reach too narrowly, or lacked hard evidence that the cartel had a wider reach.

${ }^{13}$ The mean number of mergers per cartel is almost identical for the 64 cartels for which we have market share data (1.53) and the 20 for which we do not (1.50).
} 


\section{Merger intensity after cartel breakdown}

One potential approach for testing Hypotheses $\mathbf{H 1}$ and $\mathbf{H 2}$ would be a conventional difference-in-differences (DiD). However, we reject this option for various practical ${ }^{14}$ and conceptual ${ }^{15}$ reasons and opt instead for a methodology derived from survival analysis. This provides a relatively simple, but elegant test of the hypotheses by focusing on the shape of the survival curve, that is the time path of mergers in the post-breakdown period.

The approach is explained in full below, but some descriptive statistics help set the scene. Figure 1 plots the cumulated number of mergers between former cartelists, pooled across all the cartels, with time measured in months after each cartel's breakdown. In aggregate (the bold line), 50\% of these mergers occurred within just 54 months of cartel breakdown, and the merger rate is visibly higher within these early years than in the years thereafter. Defining an "early merger" as one which occurs within 54 months of breakdown, the mean number of "early mergers" per firm was 0.02 per annum, while the rate fell to 0.007 in the later years. In a very approximate way one could think of the early years as the treatment (where merger activity is directly influenced by cartel breakdown), while the following years are the control (sufficiently long after breakdown not to have been triggered by the shock of cartel-breakdown).

Support for this interpretation is provided by aggregate published data on mergers

\footnotetext{
${ }^{14}$ Identifying appropriate control markets for such a large sample would be problematic. Typically, most cartel markets are identified by the EC at a very disaggregated level (see Table 7), and this means that invariably the most suitable control markets, in terms of similar demand and cost conditions, lie within the same 3 or 4 digit industries as the cartels. As such, they are very often populated by the same large diversified multinationals, and therefore unlikely to be genuinely independent, as required by DiD. In addition, the costs in collecting comparable data would be considerable, given the very disaggregated market definitions, and the absence of detailed data sources for the control markets compared to the cartel markets, for which the EC cartel decision documents are our invaluable source.

${ }^{15}$ Crucially, the data are right censored: the merger history in each market is observed up to the common year of observation (2013), but the start dates differ between cartels. This means that censorship is differential across markets, and we have relatively little data on the more recent cartels, and the power of tests on these cartels would be low. Further, the key hypothesis here is not the classic before-after switch usually involved in DiD, but rather, that cartel breakdown is a shock, stimulating a burst of merger activity which then gradually tails offs over time.
} 
Figure 1: Cumulated number of mergers after cartel breakdown

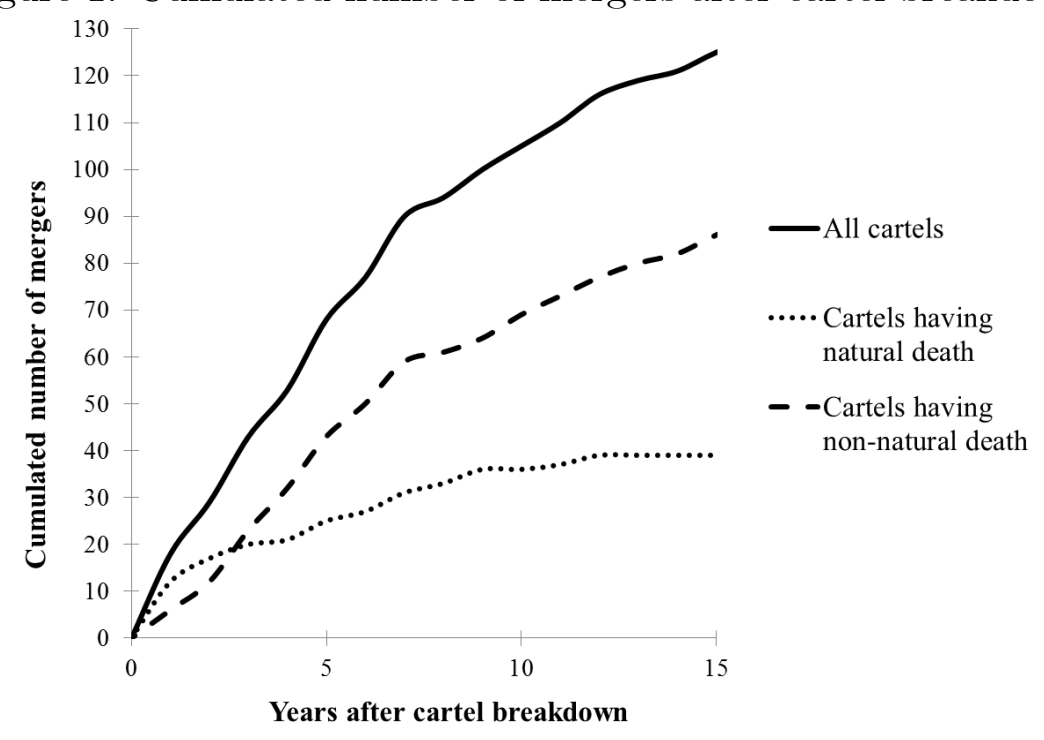

during the relevant period. UK time series statistics for all mergers involving firms with assets of more than $£ 1$ million over the period 1998-2012 record an average merger rate per firm per annum of also $0.007 .{ }^{16}$ To better reflect the geographical and industry composition of our sample we also compared with EU aggregate statistics, but in this case for manufacturing only (more than $80 \%$ of our sample were in the manufacturing sector). The EU average annual merger/firm (firms with more than 10 employees) rate in 2005-2006 is $0.016 .{ }^{17}$ In our sample of manufacturing industries the annual rate is 0.033 for early mergers and 0.013 for later mergers. So in both cases, the merger rate in the later years of our sample coincides with 'typical' rates, while the rate in the early years following cartel breakdown is 2-3 times higher. ${ }^{18}$

Returning to Figure 1, the concavity of the aggregate curve is consistent with Hypothesis H1. Figure 1 also disaggregates by whether or not the cartel had broken

\footnotetext{
${ }^{16}$ Source: UK Office for National Statistics, Mergers and Acquisitions involving UK companies.

${ }^{17}$ Source: DG ECFIN, European Commission, Mergers and Acquisitions Note.

${ }^{18}$ The advantage of using the UK data as comparator is that they yield a consistent time series over roughly the appropriate time period. Alternatively, the EU data are obviously more relevant geographically and for the affected industries, but only publicly available for 2005 and 2006 .
} 
down before detection, and the concavity is even more pronounced for the subset which had broken down before detection (shown as having 'natural death'), and this is consistent with H1a.

However, this preliminary descriptive evidence is not in itself conclusive support for our hypotheses for two reasons. First, because the population of all former cartelists (and thus all potential mergers) must decline over time due to exit by acquisition, this curve does not necessarily imply concavity in the merger rate. Second, and more fundamentally, due to variability across cartels in the date of breakdown, there is considerable heterogeneity in the number of periods observed post-breakdown. The mean sample observation period is 166 months, but this varies from 60 to 347 months. This means heterogeneity in the composition of the pool depicted in the figure, in which later observations are based on increasingly fewer cartels.

It is for precisely these reasons that we employ hazard rates, which allows for differential censorship within the sample. ${ }^{19}$ The basic intuition is as follows. In each market there may be a merger at some time after cartel breakdown - initially suppose only one merger. Then for a sample of markets there is an aggregate survival curve which shows the growth in the number of markets which have had a merger. This is depicted in terms of the number of years since breakdown - this is not calendar time since the date of breakdown varies between cartels. Associated with this is the hazard rate, which shows the probability of merger occurring in a random market $t$ years after breakdown, given that no merger had previously occurred. Our central hypothesis - (H1) - can be tested by examining the behaviour of the pooled hazard curve over time. The counterfactual in this case would be that the hazard rate is constant, which is undisturbed by the event of cartel breakdown. On the other hand a monotonically declining hazard rate in the years after breakdown would indicate that breakdown was a shock which stimulated mergers, which then gradually subsides over later years.

\footnotetext{
${ }^{19}$ The fact that we only observe relatively short post-breakdown periods for the most recent cartels also partly accounts for the fact that no mergers have been observed in half the markets. The simple correlation coefficient between length of observation period and number of mergers is +0.347 .
} 
This would be a standard application of single-event survival analysis, ${ }^{20}$ in which the clock starts ticking in any market when a cartel breaks down, and the event which subsequently may (or may not) occur is a merger. In Section 4.2 we show how the model can be made more general by allowing for multiple mergers, which occurs in many of the markets in our sample.

\subsection{The hazard model}

For this purpose, we require a distribution to describe the shape of the survival curve which is sufficiently flexible to have an increasing, decreasing, or constant hazard rate. There are a number of alternatives, but because of its simplicity, we employ the Weibull distribution, for which the hazard is:

$$
h(t)=\lambda \rho t^{\rho-1}, t \geq 0
$$

$\rho$ and $\lambda$ are conventionally referred to as the shape and scale parameters of the distribution. The scale $(\lambda)$ parameter captures the pace of merger activity, and in cross-industry analysis we can allow this to differ between markets. The shape parameter is key for our purposes: if $\rho=1$ the hazard is constant, with $\rho<1$ it is monotonically decreasing, and with $\rho>1$ it is monotonically increasing. Thus, our hypothesis that merger activity in the years immediately following cartel breakdown is more intense can be tested by:

\footnotetext{
${ }^{20}$ Survival analysis originates from health applications in which the event of interest is time until failure; for example, it might be a sample of patients who have had some medical device (such as an implant) fitted, and the subject of the study is how long before the implant fails (if at all). Patients are all observed at the same point in time, although they have had their implants at different times in the past. For some patients the implant may not yet have failed, but for others it has, at varying intervals after the treatment. Here, we substitute the date of cartel breakdown for the date of implant and the date of merger for 'failure'. As far as we know, there are no previous similar applications of survival analysis to mergers. Levenstein and Suslow (2006) and others have successfully employed survival analysis for cartel duration, where failure is naturally defined by breakdown, but our application differs from theirs in that we focus on the shape of the hazard curve, whilst accounting for the additional problem of multiple failures (mergers) of cartels.
} 


$$
\begin{aligned}
& H_{0}: \quad \rho=1 \\
& H_{1}: \quad \rho<1
\end{aligned}
$$

In effect, the null is that in each market there is a constant (but different) underlying merger rate (hazard). However, our hypothesis (H1) is that in the postbreakdown period, the hazard is highest immediately after breakdown, but gradually declines over time - with mergers more likely to be observed in the years immediately post-breakdown, but then declining gradually thereafter.

\subsection{Allowing for multiple mergers}

We now show how this methodology can be adapted to allow for multiple mergers in each market using a recurrent events survival model. To illustrate the possible modelling options, Figure 2 plots the history of a given market, in which there are three mergers, as shown on the central line. The two most commonly ${ }^{21}$ used methods to allow for recurrent events (mergers) differ in what is assumed about when individuals (markets) are entered into the risk set (exposed to the risk of a merger). First (shown below the central line), time is measured from the previous event: it starts at the time of the cartel breakdown, but each subsequent interval is measured from the preceding merger. Second, (shown above the central line), each interval is measured from the date of cartel breakdown, regardless of preceding mergers, if any.

Thus, depending on how intervals are treated, there are three alternatives. Firstly, one could ignore recurrent events and focus only on the time at which the first merger occurs (irrespective of how many mergers are to follow). We refer to this as the 'naive' model (Model 1). Secondly, in allowing for recurrent mergers we could assume that the waiting times between mergers are dependent and thus, for every merger, time starts from the preceding event (renewed entry - Model 2). Thirdly, one could assume

\footnotetext{
${ }^{21}$ See Andersen and Gill (1982), or Prentice, Williams and Peterson (1981) .
} 
Figure 2: Alternative treatments of recurrent events

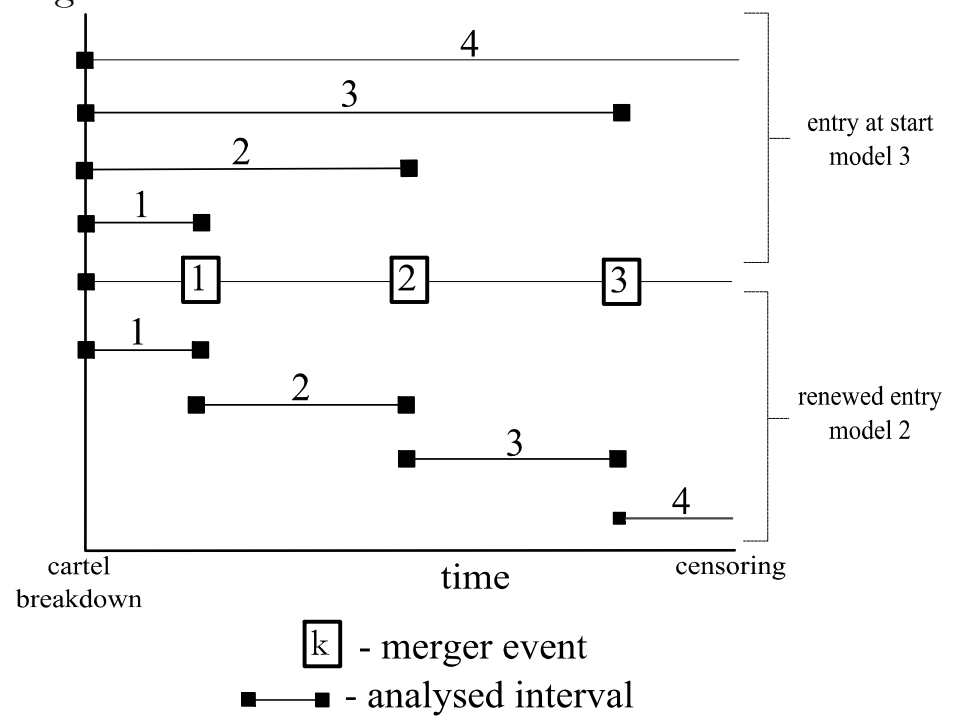

that every merger is timed from the start of the study (entry at start - Model 3).

Models 2 and 3 can be thought of as setting two bounds on the estimate of $\rho$ when multiple mergers can happen in an industry. In Model 2 each industry spends a relatively shorter time in the risk set (time starts at previous event), which means that we are more likely to have many short spells and few long spells in the sample, implying that $\rho$ should be the lowest in these models. In Model 3 we are likely to have some shorter but also many longer spells, implying a higher $\rho$.

\subsection{Results}

The MLE estimates of $\rho$ for all three models are shown in Table 1. To account for the possible dependence (ties) between failure times (subsequent mergers), standard errors used to calculate the confidence intervals are based on a 'robust' variancecovariance matrix. ${ }^{22}$ Our preference is for model 3 since model 1 discards important information on subsequent mergers, and model 2 attaches no special importance to the cartel breakdown as the main stimulus to mergers. Nevertheless, initially we

\footnotetext{
${ }^{22}$ See the Online Appendix for further explanation.
} 
report results for all three models in order to establish the robustness of the main results.

There are four alternative samples: the full sample of all cartels with either all transactions (including JVs) or mergers only; then the same split, but only for those cartels with natural breakdowns.

Table 1: Weibull $\rho$ estimates for the three alternative treatments of recurrent events

\begin{tabular}{lcccc}
\hline & \multicolumn{2}{c}{$\begin{array}{c}\text { All cartels } \\
(N=214)\end{array}$} & \multicolumn{2}{c}{$\begin{array}{c}\text { Cartels with natural } \\
\text { breakdown }(N=75)\end{array}$} \\
\hline & All transactions & Mergers only & All transactions & Mergers only \\
\hline $\begin{array}{l}\text { Model 1 } \\
\text { (naive) }\end{array}$ & 0.617 & 0.568 & 0.537 & 0.49 \\
\hline $\begin{array}{l}\text { Model 2 } \\
\text { (renewed entry) }\end{array}$ & {$[0.508,0.750]$} & {$[0.464,0.696]$} & {$[0.391,0.739]$} & {$[0.348,0.691]$} \\
\hline $\begin{array}{l}\text { Model 3 } \\
\text { (entry at start) }\end{array}$ & $0.905,0.910]$ & {$[0.587,0.895]$} & {$[0.447,0.703]$} & {$[0.397,0.716]$} \\
\hline
\end{tabular}

${ }^{1} 95$ percent confidence intervals in brackets.

As can be seen, $\rho<1$ is robust across all three models and all samples.

Result 1: $\quad$ There is higher merger activity immediately following cartel breakdown, which then gradually diminishes over time - as predicted by $\boldsymbol{H} \mathbf{1}$.

This result is significant at the $95 \%$ level except for Model 3 for the full sample, for which significance is at the $90 \%$ level.

When the model is estimated only for the sub-sample of cartels which were detected after natural breakdown ('natural breakdown' column), the MLE estimates of $\rho$ are lower and now very significantly (99\% level) less than unity in all three models:

Result 1a: For cartels that died a natural death, the above result is even stronger statistically - this is consistent with $\mathbf{H 1 a}$. 


\subsection{Allowing heterogeneity across industries}

So far, these results are conditional on the assumption that the Weibull parameters are constant across all markets, but this is now relaxed by allowing the underlying merger rate to vary across markets, using an exponential link function: $\lambda=e^{\boldsymbol{\beta}^{\prime} \mathbf{x}_{i}\left(t_{j}\right)}$, where $\mathbf{x}_{i}$ is a vector of covariates.

The most important of these for our purposes is market structure, but various cartel characteristics should also be relevant, and these are included as control variables. The nature of the agreement and organisation of the cartel are devices designed to facilitate coordination within the cartel, and without them, uncoordinated collusion may be impracticable. We capture this empirically by distinguishing cartels which were market-sharing $(m s)$ as opposed to price-fixing $(p f)$. Some forms of market sharing (notably territorial and/or customer allocations) are largely self-enforcing because defection is transparent, and if so, should still be feasible for tacit collusion. Similarly, the cartel ringleader $(r l)$ is an organisational response to problems of coordination, monitoring and enforcement. If so, it is less likely that collusion could survive a cartel bust and implicitly the loss of its leader, without restructuring. The coverage of the cartel (the proportion of industry sales accounted for by cartelists) might also reflect the external stability of not only the cartel, but also subsequent tacit coordination. We use the longevity of the cartel (duration) as a proxy for cartel success to test whether the long-standing familiarity with competitors (due to involvement in the same cartel) reduces the transaction costs of integration via a subsequent merger, because of greater trust and less uncertainty.

Table 2 reports estimates for the full sample and our preferred Model $3 .^{23}$ There are two specifications, depending on how market structure is measured: in (1) we use $H H I$, but in (2) it is replaced by its two constituent parts firm numbers $(n)$ and size

\footnotetext{
${ }^{23}$ The two other survival models yield very similar results. The 'natural death' sub-sample is too small for rigorous testing of a model, which now also includes 8 covariates: the core result, $\rho<1$ is robustly significant, but the standard errors of the covariates increase due to small sample size, reducing their significance levels. The results are for all transactions (JVs as well as mergers); but are unchanged if the equations are estimated for mergers only (excluding JVs). All these other estimates are available on request from the authors.
} 
asymmetries (measured by the coefficient of variation of market shares, $C V^{24}$ ). By decomposing $H H I$ into $n$ and $C V$, we are able to focus more precisely on the role of asymmetry within concentration, which is of particular interest for coordination. ${ }^{25}$ Where size asymmetries are large, this implies the presence of a dominant firm and, without the organisational advantages of the cartel, mergers may be necessary to consolidate the leader's position. ${ }^{26}$

The two key findings in this table are that $\rho$ remains significantly less than unity, and that the merger rate is inversely related to concentration. Thus, H1 is still confirmed when we allow for heterogeneity between cartels in their underlying merger rates; and, $\mathbf{H} \mathbf{2}$ is confirmed:

Result 2: $\quad$ The underlying merger rate is lower in more concentrated markets; where market shares are more symmetric, and there are fewer firms.

As anticipated earlier, Result 2 is open to alternative explanations: it may indicate that mergers in concentrated markets are more likely to be deterred by potential CA intervention; but alternatively it may be that these markets are already sufficiently concentrated to sustain tacit collusion without further mergers. The result on symmetry of shares suggests that this effect is driven mostly by markets in which

\footnotetext{
${ }^{24}$ The coefficient of variation is a natural measure of asymmetry in the HHI index. It is easily shown that: $H H I=\sum_{i=1}^{n} s_{i}^{2}=\left(1+C V^{2}\right) / n$. where $n$ is number of firms, $s$ is the market share of firm $i$ and $C V$ is the coefficient of variation.

${ }^{25}$ On collusion and symmetry, see, inter alia, Mason et al. (1992), Lambson (1995), Davidson and Deneckere (1990) Davidson \& Deneckere (1990), Pénard (1997) and Ivaldi et al. (2003) . Similarly, Vasconcelos (2005) finds that collusion is hindered by asymmetry-increasing mergers, as do Compte et al. (2002), but only if aggregate capacity in the market is limited.

${ }^{26}$ This is the single dominance story, where collusion may work through price leadership (Mouraviev and Rey 2011), but others show that some level of asymmetry is conducive to collusion (Ganslandt, Persson and Vasconcelos 2012), rather than forbearance amongst a small group of equals. Mouraviev and Rey (2011) find that in a Bertrand setting, price leadership restores the scope for (perfect) collusion in markets where collusion would not be sustainable otherwise. Ganslandt, Persson and Vasconcelos (2012) introduce an indivisible cost of collusion, which one of the firms in the collusion has to bear, and which creates an incentive for firms to make markets more asymmetric by mergers. The intuition behind this is that the indivisible cost should be borne by a single (large) firm. In this setting firms may merge to increase asymmetry. Andreoli-Versbach and Franck (2013) show that in the Italian retail petrol market price leadership work only after the market leader introduced a policy of sticky prices. Harrington (2006) suggests that it is typically one firm who undertakes the price and quantity monitoring tasks in a cartel.
} 
Table 2: Weibull hazard rates, allowing for heterogeneity across markets

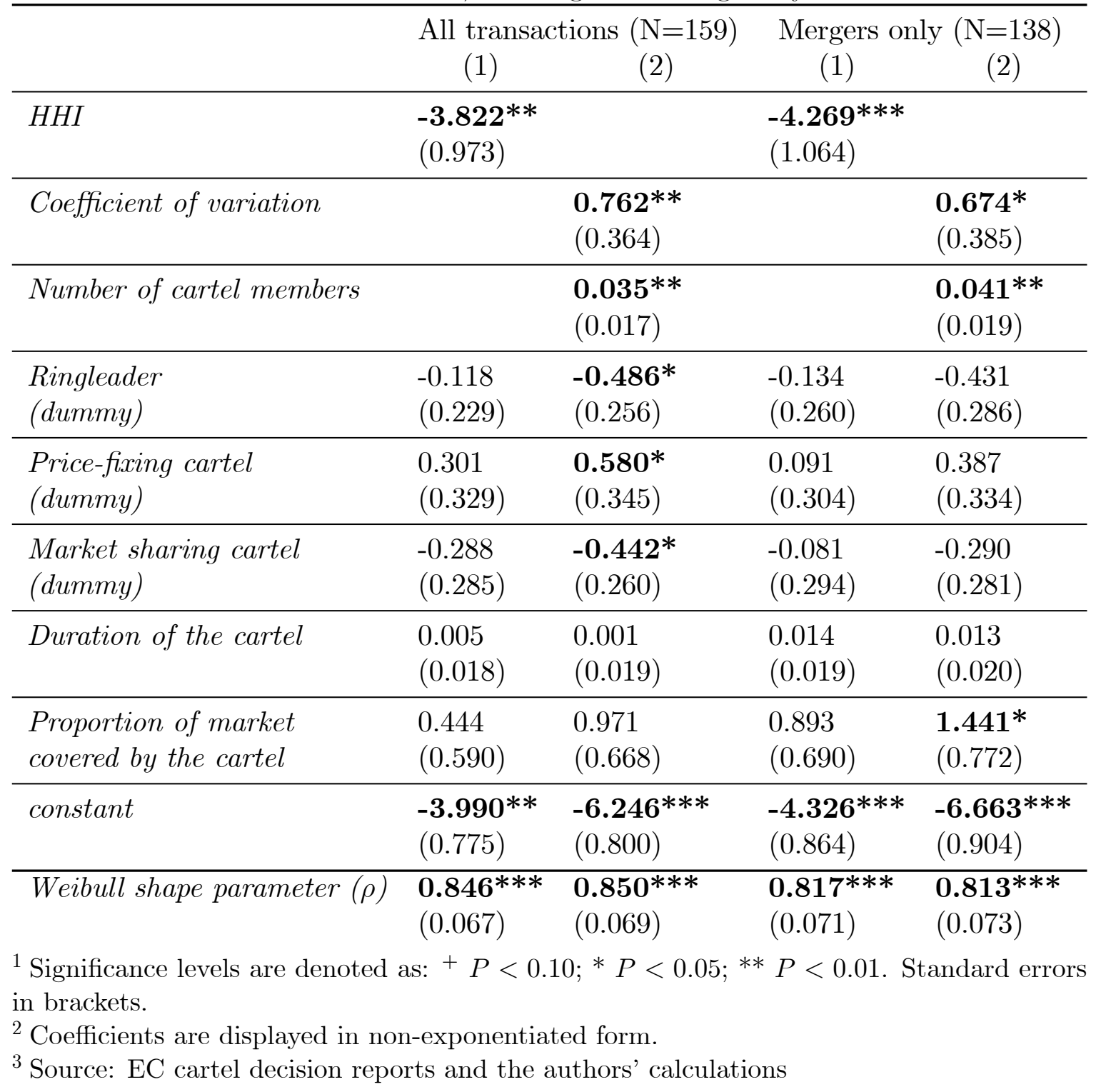


mergers are more likely to have coordinated effects. But again, this may reflect deterrence (more symmetry and fewer firms typically imply less likely merger approval) or because these markets are already conducive to collusion. ${ }^{27}$

The results on the control variable covariates are mixed, and unstable between the two equations. Weakly significant results with expected signs are found in equation 2: market sharing cartels have lower, and price fixing cartels higher, merger rates. ${ }^{28}$ Cartels with a ringleader are less likely to have subsequent merger activity, perhaps because followers have learned the benefit of following the leader's price increases, and this continues even once the former cartel has been disbanded - mergers are not an alternative to the function of the ringleader (notably punishment). However, we find no evidence that either the duration ${ }^{29}$ of the cartel, as a proxy for cartel success, or the coverage of the cartel has significant impact.

\section{$5 \quad$ Assessing competing explanations}

The above results provide confirmation of the key hypotheses of the paper, but they cannot discriminate between the alternative explanations - tacit collusion versus market efficiency. In this section therefore, we apply two screens, based on more disaggregated data on the individual mergers, to assess how many of them might have coordinated effects.

\footnotetext{
${ }^{27}$ Because we focus on the hazard of mergers (the probability of an imminent merger conditional on previous merger history) there is no need to control for the fact that with every merger there are fewer firms in the market and thus the probability of mergers is reduced.

${ }^{28}$ In a slightly modified set of models we controlled for the ordering of subsequent mergers by including a covariate counting the number of previous mergers. Estimates remain in the same region. These results are available on request from the authors.

${ }^{29}$ Although we found that early mergers differ in the time lag between the announcement of the transaction and the actual transaction consummation date: 86 days for early mergers (mergers before the median duration), and 159 days for late mergers (mergers after the median duration). This may imply smaller transaction costs for early mergers - probably due to the familiarity between the merging parties.
} 


\subsection{Market share analysis: the structural screen}

The purpose here is to assess how many of the mergers might have had the potential for coordinated effects, judged by structural indicators. To do this, we estimate how each merger affects the market structures of the industry concerned. These are hypothetical estimates in two respects: (1) the market share of a newly merged firm is assumed to be the combined shares of the two merging parties, ${ }^{30}$ and (2) this assumes that the CA does not intervene. ${ }^{31}$

Table 3 shows the results, employing a simple typology which uses data only on the shares of the two largest firms $\left(S_{1}\right.$ and $\left.S_{2}\right)$ in each market. A market involves single dominance $(S D)$ if the largest firm has at least $50 \%$ of the market. If not, there may be collective dominance $(C D)$ if the largest two firms have at least $50 \%$. Otherwise, the market does not involve dominance $(N D)$. Although very simple, this classification corresponds broadly with traditional definitions of market dominance used in the competition policy literature. For present purposes, we are most interested in $C D$, that is coordinated effects.

Table 3 shows how many markets were in each category before and after the mergers. So for example, 25 markets involved no dominance at the time of cartel breakdown; in 20 of these there were mergers, and in 8 of these, the effect was to shift the market from ND to CD.

As can be seen, most $(39 / 64=60 \%)$ markets already involved dominant firms at the time of their breakdown - usually collective dominance (33). It is also clear that mergers were less frequent in markets with already dominant firms: in only 30\% (12 of 39) of $C D / S D$ markets, as opposed to $80 \%$ of the $N D$ markets. Neither of these findings is very surprising: we would expect a large number of cartel markets to be concentrated, with symmetric shares amongst leading firms. The negative result on

\footnotetext{
${ }^{30}$ This is conventional CA practice in merger investigations. This is subject to two obvious qualifications: (i) most oligopoly theory suggests that following merger, any nearly merged firm will raise price and contract scale rather than maintain it at the combined pre-merging scales of the parties, (ii) we abstract from any other changes in market structure which are independent of the merger.

${ }^{31}$ In fact, in very few cases were there interventions by either the EC or national authorities, Davies and Ormosi (2014) .
} 
Table 3: Number of cartels and mergers by the cartel market's structure

\begin{tabular}{cccccc}
\hline & & & Structure after mergers \\
\hline $\begin{array}{c}\text { Structure at } \\
\text { breakdown }\end{array}$ & $\begin{array}{c}\text { Number of } \\
\text { cartels }\end{array}$ & $\begin{array}{c}\text { Number of cartels } \\
\text { with mergers }\end{array}$ & SD & CD & ND \\
\hline Single dominance (SD) & 6 & 1 & 6 & & \\
Collective dominance (CD) & 33 & 11 & 1 & 32 & 17 \\
No dominance (ND) & 25 & 20 & & 8 & 17 \\
\hline total & 64 & 32 & 7 & 40 & 17 \\
\hline
\end{tabular}

${ }^{1}$ In markets where there was more than one merger, these figures show their cumulated effect.

${ }^{2} \mathrm{SD}$ denotes a market in which the largest firm has a market share of at least $50 \%$; CD where the two largest firms have a combined share of at least $50 \%$; ND is neither.

HHI in Table 2 has already shown that there are relatively fewer mergers in more concentrated markets. A further finding from the table provides the answer to our question:

Result 3: $\quad$ In 19 markets (30\%), the market share screen raises concern on potential coordinated effects.

These are the 11 in which there was already collective dominance before the mergers, and the 8 in which there was not previously collective dominance, but in which the mergers would create CD.

It is these markets in particular, for which a structural screen should suggest the potential for coordinated effects. Of course, market shares alone are insufficient evidence that the mergers were either motivated by, or resulted in, anti-competitive behaviour, but they do provide a screen.

\subsection{Event studies}

Event studies are a well-established methodology for assessing whether mergers will have coordinated effects - an efficient capital market should react to announcement of such a merger by increasing the values of both the acquiring firm and its rivals. We employ this methodology here, and pose two questions. First, is there evidence 
that mergers after cartel breakdown differ from 'typical' mergers? In particular are they more frequently value-enhancing for the acquirers? Second, in how many of the mergers did the markets judge the effect on both acquiring and rival firms to be positive? We shall distinguish between mergers in the early years after breakdown and those in later years: as explained in Section 4, an early merger is defined as one occurring before the sample median duration (54 months after breakdown).

\subsubsection{Data on stock prices}

These data were collected for the markets in which the acquirer was listed and we could identify the exact date of the merger announcement. We were able to do this for 49 mergers ( $40 \%$ of the sample). The mean number of rivals (with stock-market data) per merger was $5 .^{32}$

The firms' and market returns were estimated from the Thomson One Banker dataset. For normal returns we used a window of 240 trading days, and calculated the abnormal returns as the difference between firm i's return and the market return. To eliminate problems from information leakage around the event date, we cumulated these abnormal returns (CAR) for the event window. Three alternative windows were used: $[-1,1],[-3,3]$, and $[-5,5] .^{33}$

Our observations on the date of the event (date of merger announcement) are from publicly available sources, typically Google. Inevitably, there is the possibility of imprecision in the sense that information on the merger might have leaked out to investors before it was first published in business dailies. For this reason we would be reluctant to employ overly narrow event windows; on the other hand, too wide windows are more likely to include confounding effects. Therefore in the following we report results based on the $[-3,3]$ window. ${ }^{34}$

\footnotetext{
${ }^{32}$ Because it is not directly relevant to our analysis, we did not include 'target' companies in our analysis. Nevertheless, from the 49 mergers only 18 'target' companies were listed (and 10 of these were joint ventures).

${ }^{33}$ These windows are the most frequently used in merger related event studies.

${ }^{34}$ Results with different event windows differed in magnitude but not in their sign, and are available from the authors on request.
} 


\subsubsection{Results}

As a preliminary, we find that the mean CAR for acquiring firms in early mergers is significantly positive, but is not for later mergers. Our reading of previous general event studies on mergers, such as Jarrell and Bradley (1980), Ruback and Jensen (1983) , and Andrade, Mitchell, and Stafford (2001) is that, typically, the acquiring company suffers a reduction or no change in its valuation as a result of the merger.

Table 4: Financial markets' assessment of the mergers: acquiring firms' average CARs

\begin{tabular}{ccccc}
\hline & \multicolumn{2}{c}{ All transactions } & \multicolumn{2}{c}{ Mergers only } \\
\hline & $N$ & CAR & $N$ & CAR \\
\hline Early mergers & 24 & $\mathbf{0 . 0 3 5}^{*}$ & 18 & $\mathbf{0 . 0 4 4}$ \\
& & $(0.015)$ & & $(0.018)$ \\
\hline Late mergers & 25 & 0.000 & 19 & -0.006 \\
& & $(0.018)$ & & $(0.020)$ \\
\hline
\end{tabular}

${ }^{1}$ Note: Early (late) mergers are within (beyond) the median duration from cartel breakdown.

${ }^{2}$ Significance levels are denoted as: ${ }^{+} P<0.10$; $P<0.05 ;{ }^{* *} P<0.01$. Standard errors in brackets.

This suggests that, in our case, the later mergers are fairly typical of what has been found in previous literature, but that early mergers are more likely than usual to be value-enhancing for acquiring firms. ${ }^{35}$ This leads to the following result:

Result 4: $\quad$ Mergers in the early years after cartel breakdown are more than usually value-enhancing for acquiring firms.

Turning to the rivals, as Stigler (1950) first observed, in some circumstances, it might be advantageous for firms to reside outside a merger: "If there are relatively few firms in the industry, the major difficulty in forming a merger is that it is more

\footnotetext{
${ }^{35}$ Loughran and Vijh (1997) found that cash-funded mergers are more likely to have positive CAR. However, we found no difference between early and late mergers regarding the funding of the merger.
} 
profitable to be outside a merger than to be a participant." Mergers also increase market concentration and hence facilitate collusion (Stigler 1964), which may also be advantageous for rival firms. Fee and Thomas (2004), Shahrur (2005), Duso et al. (2007) , and Clougherty and Duso (2009) all look at the effect of mergers on rival firms - and offer a general support that rival firms benefit from such merger events. ${ }^{36}$

Table 5 records the number of cases (for mergers only ${ }^{37}$ ) for which acquirer's value increased $(\mathrm{A}+)$, and then, the number of these for which the rivals' values also increased $(\mathrm{R}+) \cdot{ }^{38}$

Table 5: Number and \% of cases where the acquirer and the rival CARs are positive

\begin{tabular}{rcccc}
\hline & & All & $\mathrm{A}+$ & $\mathrm{A}+\mathrm{R}+$ \\
\hline \multirow{2}{*}{ Early mergers } & $\#$ & 18 & 15 & 10 \\
& $\%$ & & 0.833 & 0.556 \\
\hline \multirow{2}{*}{ Late mergers } & $\#$ & 19 & 9 & 4 \\
& $\%$ & & 0.473 & 0.21 \\
\hline \multirow{2}{*}{ Total } & $\#$ & 37 & 24 & 14 \\
& $\%$ & & 0.648 & 0.378 \\
\hline
\end{tabular}

${ }^{1}$ Early (late) mergers are within (beyond) the median duration from cartel breakdown

${ }^{2} \mathrm{~A}+$ denotes the number number of mergers in which the acquirer's CAR are positive, amd A+R+ denotes the number of those in which the rivals' CAR are also positive.

As can be seen, over $80 \%$ of early mergers are value generating for acquirers (market power or efficiency) while less than half of later mergers are. This is as expected given Result 3.

In addition, the proportion of these which are also beneficial to rivals is larger for early than late mergers. Taken together, and identifying $(\mathrm{A}+\mathrm{R}+)$ as coordinated

\footnotetext{
${ }^{36}$ Other reasons include the information effect: the merger signals the possibility that the rival may also be a merger target soon, see: Eckbo (1983) and Song and Walking (2000) .

${ }^{37}$ Similar magnitudes were obtained when all transactions were included in the sample. These results are available on request from the authors.

${ }^{38}$ Typically there was more than one rival, and where some recorded positive, and some negative, CARs, we show the predominant effect.
} 
effects leads us to our final result:

Result 5: $\quad$ Half of early mergers have the potential to be anti-competitive, whilst only one quarter of late mergers do.

Taking the results of these two screens together suggests that mergers in response to a cartel breakdown will often, but by no means always, lead to market structures which are consistent with the potential for coordinated effects, and the financial markets expect this to happen in a sizeable proportion of cases.

\section{Conclusions}

This paper confirms that after a cartel breaks down, there is typically a period of increased merger activity amongst the former cartelists. Its methodological novelty derives from an application of survival analysis to an unbalanced pooled sample of cartels with differing dates of breakdown and therefore differing periods of observation.

It finds that the increased merger activity post breakdown is most pronounced in cartels which are detected after they have already broken down. This might be because these are 'failed' cartels, and if firms are to re-instate collusion, albeit tacit, they will need to create a structure which facilitates tacit collusion, by merger. It also finds that merger activity post-breakdown is less pronounced in markets which are already concentrated. This might be because tacit collusion is already possible in these markets, without further consolidation through merger. On the other hand, it may be that the fear of CA intervention deters firms from merging in already concentrated markets.

Therefore, our results are consistent with what is the prevailing explanation in the existing literature, that the coordinated effects motivation drives mergers. But there is also an alternative explanation, with very different policy implications. We refer to this as the "efficiency explanation": the breakdown of a cartel has the desired effect (for the CA), as competition now stiffens, weaker marginal firms exit often by acquisition. 
In the final part of the paper, we run the sample markets through two alternative screens in order to gauge how frequently the anti-competitive explanation might dominate. In the first, we compute the expected changes in market structure and examine how many would satisfy the necessary structural conditions for CAs to pursue a coordinated effects theory of harm. In the second, we undertake an event study analysis of the financial markets' reactions to these mergers. Here we focus on how frequently the valuations of both acquirers and rivals are marked up as a consequence of merger announcement. Both of these screens suggest that the coordinated effects explanation applies in at least a large minority of cases. For these markets at least the evidence points in the direction of mergers as a second best means of re-instating (tacit) collusion, once a cartel has broken down.

\section{References}

Andersen, Per Kragh, \& Gill, Richard David. 1982. Cox's Regression Model for Counting Processes: A Large Sample Study. The Annals of Statistics, 10(4), $1100-1120$.

Andrade, Gregor, Mitchell, Mark, \& Stafford, Erik. 2001. New Evidence and Perspectives on Mergers. The Journal of Economic Perspectives, 15(2), 103-120.

Andreoli-Versbach, Patrick, \& Franck, Jens-Uwe. 2013. Actions Speak Louder Than Words: Econometric Evidence to Target Tacit Collusion in Oligopolistic Markets. Munich Discussion Paper, 2013-8.

Bittlingmayer, George. 1985. Did Antitrust Policy Cause the Great Merger Wave? Journal of Law and Economics, 28(1), 77-118.

Bresnahan, Timothy F., \& Reiss, Peter C. 1991. Entry and Competition in Concentrated Markets. Journal of Political Economy, 99(5), 977-1009.

Clougherty, Joseph A., \& Duso, Tomaso. 2009. The Impact of Horizontal Mergers 
on Rivals: Gains to Being Left Outside a Merger. Journal of Management Studies, 46(8), 1365-1395.

Compte, Olivier, Jenny, Frédéric, \& Rey, Patrick. 2002. Capacity Constraints, Mergers and Collusion. European Economic Review, 46(1), 1-29.

Connor, John M. 2001. "Our Customers Are Our Enemies": The Lysine Cartel of 1992-1995. Review of Industrial Organization, 18(1), 5-21.

Cook, Richard J., \& Lawless, Jerald F. 2007. The Statistical Analysis of Recurrent Events. Springer.

Cosnita-Langlais, Andreea, \& Tropeano, Jean-Philippe. 2013. Fight Cartels or Control Mergers? On the Optimal Allocation of Enforcement Efforts Within Competition Policy. International Review of Law and Economics, 34, 34-40.

Davidson, Carl, \& Deneckere, Raymond. 1990. Excess Capacity and Collusion. International Economic Review, 31(3), 521-41.

Davies, Stephen, \& Ormosi, Peter. 2014. Mergers After Cartels: How Markets React to Cartel Breakdown. CCP Working Paper, 14-1.

Duso, Tomaso, Neven, Damien J., \& Roller, LarsĄ-Hendrik. 2007. The Political Economy of European Merger Control: Evidence Using Stock Market Data. Journal of Law and Economics, 50(3), 455-489.

Eckbo, B. Espen. 1983. Horizontal Mergers, Collusion, and Stockholder Wealth. Journal of Financial Economics, 11, 241-273.

Evenett, Simon J., Levenstein, Margaret C., \& Suslow, Valerie Y. 2001. International Cartel Enforcement: Lessons from the 1990s. The World Economy, 24(9), 12211245 .

Fee., Edward C., \& Thomas, Shawn. 2004. Sources of Gains in Horizontal Mergers: Evidence from Customer, Supplier, and Rival Firms. Journal of Financial Economics, 74, 423-460. 
Fonseca, Miguel A., \& Normann, Hans-Theo. 2012. Explicit Vs. Tacit Collusion The Impact of Communication in Oligopoly Experiments. European Economic Review, 56(8), 1759-1772.

Ganslandt, Mattias, Persson, Lars, \& Vasconcelos, Helder. 2012. Endogenous Mergers and Collusion in Asymmetric Market Structures. Economica, 79(316), 766-791.

Harrington, Joseph. E. 2004. Post-Cartel Pricing During Litigation. The Journal of Industrial Economics, 52(4), 517-533.

Harrington, Joseph. E. 2006. How Do Cartels Operate? Foundations and Trends in Microeconomics, 2(1), 1-105.

Hüschelrath, Kai, \& Smuda, Florian. 2012. Do Cartel Breakdowns Induce Mergers? Evidence from EC Cartel Cases. European Competition Journal, 9(2), 407-429.

Ivaldi, Marc, Jullien, Bruno, Rey, Patrick, Seabright, Paul, \& Tirole, Jean. 2003. The Economics of Tacit Collusion. Final Report for DG Competition, European Commission.

Jarrell, Gregg A., \& Bradley, Michael. 1980. The Economic Effects of Federal and State Regulations on Cash Tender Offers. Journal of Law and Economics, 23, 371-407.

Kovacic, Willian E., Marshall, Robert C., \& Raiff, Matthew E. 2007. Lessons for Competition Policy from the Vitamins Cartel. Emerald Group Publishing Limited.

Kumar, Vikram, Marshall, Robert C., Marx, Leslie M., \& Samkharadze, Lily. 2013. Buyer Resistance for Cartel versus Merger. Working Paper. Duke University.

Lambson, Val Eugene. 1995. Optimal Penal Codes in Nearly Symmetric Bertrand Supergames with Capacity Constraints. Journal of Mathematical Economics, 24(1), 1-22.

Lee, Elisa T., \& Wang, John Wenyu. 2003. Statistical Methods for Survival Data Analysis. 3rd edition edn. Wiley-Blackwell. 
Levenstein, Margaret C., \& Suslow, Valerie Y. 2006. What Determines Cartel Success? Journal of Economic Literature, 44(1), 43-95.

Lin, Danyu, \& Wei, Lee-Jen. 1989. The Robust Inference for the Cox Proportional Hazards Model. Journal of the American Statistical Association, 84(4), 1074-1078.

Marx, Leslie M., \& Zhou, Jun. 2014. The Dynamics of Mergers Among (Ex)CoConspirators in the Shadow of Cartel Enforcement. TILEC Discussion Paper No. 2014-013.

Mason, Charles F., Phillips, Owen R., \& Nowell, Clifford. 1992. Duopoly Behaviour in Asymmetric Markets: An Experimental Evaluation. The Review of Economics and Statistics, 74(4), 662-670.

Mitchell, Mark L., \& Mulherinb, J. Harold. 1996. The Impact of Industry Shocks on Takeover and Restructuring Activity. Journal of Financial Economics, 41, $193-229$.

Moon H. Song, Ralph A. Walkling. 2000. Abnormal Returns to Rivals of Acquisition Targets: A Test of the Acquisition Probability Hypothesis. Journal of Financial Economics, 55, 143-171.

Mouraviev, Igor, \& Rey, Patrick. 2011. Collusion and Leadership. International Journal of Industrial Organization, 29(6), 705-717.

Mueller, Dennis C. 1996. Antimerger Policy in the United States: History and Lessons. Empirica, 23(3), 229-253.

Pénard, Thierry. 1997. Choix de Capacités et Comportements Stratégiques: Une Approche Par la Théorie Des Jeux Répétés. Annales d'Economie et de Statistiques, 46(2), 203-396.

Prentice, Ross L., Williams, B.J., \& Peterson, Arthur V. 1981. On the Regression Analysis of Multivariate Failure Time Data. Biometrika, 68(2), 373-379. 
Ruback, Richard S., \& Jensen, Michael C. 1983. The Market for Corporate Control: The Scientific Evidence. Journal of Financial Economics, 11, 5-50.

Shahrur, Husayn. 2005. Industry Structure and Horizontal Takeovers: Analysis of Wealth Effects on Rivals, Suppliers, and Corporate Customers. Journal of Financial Economics, 76, 61-98.

Stigler, George J. 1950. Monopoly and Oligopoly by Merger. American Economic Review, 40(2, Papers and Proceedings of the Sixty-second Annual Meeting of the American Economic Asociation (May, 1950)), 23-34.

Stigler, George J. 1964. A Theory of Oligopoly. The Journal of Political Economy, $72(1), 44-61$.

Sutton, John. 1991. Sunk Costs and Market Structure. Cambridge, Massachusetts: MIT Press.

Symeonides, George. 2002. The Effects of Competition: Cartel Policy and the Evolution of Strategy and Structure in British Industry. Cambridge, Massachusetts: MIT Press.

Vasconcelos, Helder. 2005. Tacit Collusion, Cost Asymmetries, and Mergers. RAND Journal of Economics, 36(1), 39-62.

\section{A Online Appendix}

\section{A.1 Recurrent event analysis}

Following conventional notation in recurrent event analysis ${ }^{39}$ denote the merger event history in any market by $N(t)=\{n(u): u \leq t\}$, where $n(u)$ is the number of mergers

\footnotetext{
${ }^{39}$ For example a comprehensive treatment of recurrent event models in the area of biostatistics is given by Cook and Lawless (2007) .
} 
in $[0 ; t) .{ }^{40}$ We also allow for the possibility that hazard rates are a function of market and cartel characteristics (denoted by $\mathbf{X}$ ). Then the hazard (intensity) function is:

$$
h\{t \mid N(t), \mathbf{X}\}=\lim _{\Delta t \rightarrow 0} \operatorname{Pr} \frac{\left[t \leq T_{n(t)+1}<t+\Delta t \mid N(t), \mathbf{X}\right]}{\Delta t}
$$

By combining (1) and (A.1) the above three scenarios can be modelled in the following way:

1. 'Naive' model: $h(t \mid \mathbf{X})=\lambda \rho t^{\rho-1}$.

2. Renewed entry model: $h(t \mid N(t), \mathbf{X})=\lambda \rho\left(t-t_{n(t)}\right)^{\rho-1}$. This follows Andersen and Gill (1982) and the first model in Prentice et al. (1981).$^{41}$

3. Entry at start model: $h(t \mid N(t), \mathbf{X})=\lambda \rho t^{\rho-1}$. This model is loosely based on the second model in Prentice et al. (1981). ${ }^{42}$

Now consider the implication for a sample of $m$ industries, when the set of all industries is $\left\{G_{1}, G_{2}, \ldots, G_{m}\right\}$. Denote the total number of mergers in industry $G_{i}(i=$ $1,2, \ldots, m)$ by $k_{i}$. Allowing for right-censoring in each industry there are $s_{i}=k_{i}+1$ intervals in each industry. For each interval denote the total number of industries at risk by $m_{s}$, and the number of industries with mergers by $r_{s}$.

Let $t_{s 1}, t_{s 2}, \ldots, t_{s r_{s}}, t_{s r_{s}+1}^{+}, \ldots, t_{s m_{s}}^{+}$be the ordered failure (merger) times in interval $s,{ }^{43}$ with $\sum_{s \geq 1} r_{s}$ exact times, and - because the study period has a natural cutoff point at the time of writing this study - we also have $\sum_{s \geq 1}\left(m_{s}-r_{s}\right)$ right-censored intervals. The likelihood of observing this sequence is given by:

\footnotetext{
${ }^{40}$ The counting process $N(t)$ is equivalent of the random failure times $T_{1}<\ldots<T_{n(t)}$, and $n(t)$ records the cumulative number of mergers, $n(t)=\sum_{k=1}^{\infty} I\left(T_{k} \leq t\right)$, where $T_{k}$ is the time of the $k$-th merger.

${ }^{41}$ We replace the Cox $\mathrm{PH}$ model used in these papers by a fully parametric approach.

${ }^{42}$ Both Andersen and Gill (1982), and Prentice et al. (1982) used a stratified model. We opt against this, as it would require estimating parameters of a baseline hazard for each industry for each possible strata (interval), which would have been too demanding from our relatively small sample.

${ }^{43}$ For simplicity we assume that the failure process is orderly (there cannot be two mergers in the same month).
} 


$$
L=\prod_{s \geq 1}\left[\prod_{j=1}^{r_{s}} f\left(t_{j}\right) \prod_{j=r_{s}+1}^{m_{s}} S\left(t_{j}^{+}\right)\right]
$$

Where the density function $f(t)$ represents the information that can be obtained from observed uncensored survival times and the survival function $S(t)$ captures observed right-censored times.

Using the Weibull density $\left(\rho \lambda^{\rho} t^{\rho-1} e^{-(\lambda t)^{\rho}}\right)$ and survival functions $\left(e^{-(\lambda t)^{\rho}}\right)$ together with (A.2) the recurrent event, right-censored likelihood functions to be estimated for the three models described are given below. For each model we assumed that the sample is progressively censored (markets are entered at different times and the study lasts a predetermined period of time).

In the naive model there is only one interval analysed, therefore the ordered survival data is: $t_{1} \leq t_{2} \leq \ldots \leq t_{r}, t_{r+1}^{+}, \ldots, t_{m}^{+}$and the likelihood of observing this data given a Weibull distribution is:

$$
L_{1}=\prod_{j=1}^{r} \rho \lambda^{\rho} t_{j}^{\rho-1} e^{-\left(\lambda t_{j}\right)^{\rho}} \prod_{j=r+1}^{m} e^{-\left(\lambda t_{j}^{+}\right)^{\rho}}, t>0
$$

In the renewed entry model denote the gap time between two events in the same industry by $u_{s}=t_{s}-t_{(s-1)}$. In this case the ordered (observed and censored) gap times are given by: $u_{s 1} \leq u_{s 2} \leq \ldots \leq u_{s r_{s}}, u_{s r_{s}+1}^{+}, \ldots, u_{s m_{s}}^{+}$and the likelihood function:

$$
L_{2}=\prod_{s \geq 1}\left[\prod_{j=1}^{r_{s}} \rho \lambda^{\rho} u_{s j}^{\rho-1} e^{-\left(\lambda u_{s j}\right)^{\rho}} \prod_{j=r_{s}+1}^{m_{s}} e^{-\left(\lambda u_{s j}\right)^{\rho}}\right], t>0
$$

In the entry at start model the ordered survival data is: $t_{s 1} \leq t_{s 2} \leq \ldots \leq$ $t_{s r_{s}}, t_{s r_{s}+1}^{+}, \ldots, t_{s m_{s}}^{+}$and the likelihood function is:

$$
L_{3}=\prod_{s \geq 1}\left[\prod_{j=1}^{r_{s}} \rho \lambda^{\rho} t_{s j}^{\rho-1} e^{-\left(\lambda t_{s j}\right)^{\rho}} \prod_{j=R+1}^{m_{s}} e^{-\left(\lambda t_{s j}^{+}\right)^{\rho}}\right], t>0
$$

As the emphasis is on estimating $\rho$ initially we estimate $\lambda$ and $\rho$ without allowing for heterogeneity across cartels. ${ }^{44}$

\footnotetext{
${ }^{44}$ Note that $1-3$ differ from Prentice et al. (1981) not only in that they are fully parametric but also in that $\rho$ and $\lambda$ are homogeneous across intervals. Assuming different hazard functions for each time interval between events would mean estimating $\max \left(K_{i}\right) \times 2$ parameters (in the model without covariates), which we rejected for dimensionality reasons.
} 


\section{A.2 Obtaining MLE of $\lambda$ and $\rho$}

For Model 1 the MLE of $\lambda$ and $\rho$ can be obtained following procedures on parametric censored survival models, such as Lee and Wang (2003, p.178). In previous literature we did not find derivation of the MLE of the two Weibull parameters in the two recurrent-event models used in this paper therefore we briefly report how the Model 3 estimates were obtained (Model 2 is derived analogously but time is measured by $\left.u_{s}=t_{s}-t_{(s-1)}\right)$.

Denote the set of estimable parameters by $\boldsymbol{\beta}=\{\lambda, \rho\}$, then the loglikelihood function is given by :

$$
l_{3}(\boldsymbol{\beta})=\sum_{s \geq 1}\left\{\begin{array}{c}
r_{s} \ln (\rho)+r_{s} \rho \ln (\lambda)+ \\
\sum_{j=1}^{r_{s}}\left[(\rho-1) \ln \left(t_{s j}\right)-\left(\lambda t_{s}\right)^{\rho}\right]-\sum_{j=r_{s}+1}^{m_{s}}\left(\lambda t_{s j}^{+}\right)^{\rho}
\end{array}\right\}
$$

For $l_{3}(\boldsymbol{\beta})$ the MLE of $\lambda$ and $\rho$ can be obtained by solving the following two equations simultaneously:

$$
\begin{aligned}
\sum_{s \geq 1}\left\{\frac{r_{s} \rho}{\lambda}+\sum_{j=1}^{r_{s}} \rho \lambda^{\rho-1} t_{s j}{ }^{\rho}-\sum_{j=r_{s}+1}^{m_{s}} \rho \lambda^{\rho-1} t_{s j}^{+\rho}\right\} & =0 \\
\sum_{s \geq 1}\left\{\frac{r_{s}}{\rho}+\sum_{j=1}^{r_{s}} \ln \left(t_{s j}\right)-\left(\lambda t_{s j}\right)^{\rho} \ln \left(\lambda t_{s j}\right)-\sum_{j=r_{s}+1}^{m_{s}}\left(\lambda t_{s j}^{+}\right)^{\rho} \ln \left(\lambda t_{s j}^{+}\right)\right\} & =0
\end{aligned}
$$

There is no closed solution for this system so iterative techniques à la NewtonRaphson were used.

The 95\% confidence intervals given in Table 1 were obtained using:

$$
\left[\widehat{\lambda}-Z_{0.025} \sqrt{v_{\lambda \lambda}}, \widehat{\lambda}+Z_{0.025} \sqrt{v_{\lambda \lambda}}\right]
$$

and

$$
\left[\widehat{\rho}-Z_{0.025} \sqrt{v_{\rho \rho}}, \widehat{\rho}+Z_{0.025} \sqrt{v_{\rho \rho}}\right]
$$

where $Z_{0.025}$ is the 0.975 percentile point of the standard normal distribution. $v_{\lambda \lambda}$ and $v_{\rho \rho}$ are the two diagonal elements of an adjusted covariance matrix. Lin 
(1994) showed that the covariance matrix given by $\mathbf{I}^{-1}=-\partial^{2} l(\widehat{\boldsymbol{\beta}}) / \partial \beta \partial \beta^{\prime}$ does not take into account the additional correlation in the data due to the potential lack of independence among mergers in the same industry. Therefore it is not appropriate for testing or constructing confidence intervals for recurrent event data. Lin and Wei (1989) proposed dealing with this in the following way.

Divide the sample into $m$ industries $\left\{G_{1}, G_{2}, \ldots, G_{m}\right\}$, and denote the matrix of the group efficient score residuals by $\mathbf{G}$, which has dimensions $m \times 2$ because there are $m$ industries and 2 parameters to be estimated. Then the robust covariance matrix is given by:

$$
\mathbf{V}=\mathbf{I}^{-1} \mathbf{G}^{\prime} \mathbf{G I}^{-1}
$$

\section{A.3 Additional tables}

Table A1: Descriptive statistics for cartels

\begin{tabular}{rccccc}
\hline Variable & Obs & Mean & Std. Dev. & Min & Max \\
\hline Number of cartel members at breakdown & 84 & 7.393 & 5.280 & 2 & 33 \\
Cartel duration (years) & 84 & 8.317 & 6.418 & 0 & 35 \\
Coverage (cartel share of the market) & 72 & 0.843 & 0.167 & 0.220 & 1.000 \\
HHI at cartel breakdown & 64 & 0.292 & 0.136 & 0.078 & 0.844 \\
CV at cartel breakdown & 64 & 0.708 & 0.333 & 0.094 & 1.958 \\
Proportion of cartels with ringleaders & 78 & 0.333 & 0.474 & 0.000 & 1.000 \\
Proportion of market sharing cartels & 83 & 0.699 & 0.462 & 0.000 & 1.000 \\
Proportion of price fixing cartels & 83 & 0.819 & 0.387 & 0.000 & 1.000 \\
Proportion of bid rigging cartels & 83 & 0.217 & 0.415 & 0.000 & 1.000 \\
Proportion of leniency cases & 84 & 0.714 & 0.454 & 0.000 & 1.000 \\
Proportion natural breakdown cartels & 84 & 0.420 & 0.497 & 0.000 & 1.000 \\
Cartels followed by & & & & & \\
No merger & 43 & & & & \\
1 merger & 14 & & & & \\
2 mergers & 8 & & & & \\
3 mergers & 8 & & & & \\
4+ mergers & 11 & & & & \\
\hline
\end{tabular}


Table A2: List of post-breakdown Mergers, Acquisitions and Joint Ventures

\begin{tabular}{|c|c|c|c|c|c|}
\hline Cartel & Cartel breakdown & Year of Merger & Firm 1 in Merger & Firm 2 in Merger & CAR of Firm 1 \\
\hline CRT Glass & 2004 & 2008 & Asahi Glass & Schott & 0.02826 \\
\hline LCD & 2006 & 2008 & LG Philipps & Hannstar & -0.05064 \\
\hline \multirow[t]{2}{*}{ Airfreight } & \multirow[t]{2}{*}{2006} & 2011 & KLM & Martinair & \\
\hline & & 2008 & Japan Airlines & Quantas & \\
\hline \multirow[t]{2}{*}{ Prestressing Steel } & \multirow[t]{2}{*}{2002} & 2005 & Companhia Previdente & Italcables & \\
\hline & & 2004 & Companhia Previdente & Emesa-Trefilería/Industrias Galycas & \\
\hline \multirow[t]{9}{*}{ DRAM } & \multirow[t]{9}{*}{2002} & 2003 & Mitsubishi & Toshiba & 0.10064 \\
\hline & & 2003 & Mitsubishi & Hitachi & 0.01431 \\
\hline & & 2003 & Infineon & Nanya & \\
\hline & & 2003 & Elpida & Mitsubishi & \\
\hline & & 2003 & Mitsubishi & Toshiba & 0.03635 \\
\hline & & 2003 & Samsung & Toshiba & -0.04258 \\
\hline & & 2008 & Micron & Inotera (Infineon/Nanya) & 0.14818 \\
\hline & & 2011 & Hynix & Toshiba & -0.12180 \\
\hline & & 2013 & Micron & Elpida & \\
\hline \multirow[t]{4}{*}{ Power Transformers } & \multirow[t]{4}{*}{2003} & 2003 & Siemens & Alstom & 0.00951 \\
\hline & & 2004 & Areva & Alstom & \\
\hline & & 2009 & Areva & Siemens & \\
\hline & & 2010 & Alstom & Schneider/Areva & \\
\hline Removal Service & 2003 & 2007 & Team Relocations & Arthur Pierre & \\
\hline \multirow[t]{2}{*}{ Parafin Wax } & \multirow[t]{2}{*}{2005} & 2007 & Eni & Exxon & 0.01632 \\
\hline & & 2007 & Sasol & Shell & -0.03641 \\
\hline \multirow[t]{4}{*}{ GIS } & \multirow[t]{4}{*}{2004} & 2005 & Siemens & VA Tech & 0.00097 \\
\hline & & 2007 & Mitsubishi & Areva & 0.07752 \\
\hline & & 2008 & Schneider & Fuji & 0.07751 \\
\hline & & 2010 & Alstom & Areva & 0.00794 \\
\hline Rubber & 2002 & 2006 & Bayer & Dow & 0.0055 \\
\hline \multirow[t]{6}{*}{ Hydrogen Peroxide } & \multirow[t]{6}{*}{2000} & 2001 & FMC & Degussa & 0.7827 \\
\hline & & 2001 & Degussa & Edison SpA / Ausimont & \\
\hline & & 2002 & Solvay & Ausimont & 0.03157 \\
\hline & & 2002 & Degussa & Edison SpA / Ausimont & \\
\hline & & 2003 & Kemira (Polargas) & Air Liquide & 0.03334 \\
\hline & & 2012 & Solvay & Air Liquide & 0.08885 \\
\hline \multirow[t]{3}{*}{ Copper Fittings } & \multirow[t]{3}{*}{2001} & 2002 & Aalberts & Yorkshire (IMI) & -0.03219 \\
\hline & & 2005 & Aalberts & Pegler/Tomkins & 0.07313 \\
\hline & & 2006 & Aalberts & Legris / Comap & 0.07527 \\
\hline Bitumen Netherlands & 2002 & 2002 & BAM & HBG & \\
\hline Raw Tobacco Italy & 2001 & 2005 & Dimon & Transcatab & \\
\hline MCAA & 1999 & 1999 & Akzo & Hoechst & 0.07154 \\
\hline \multirow[t]{5}{*}{ Industrial Thread } & \multirow[t]{5}{*}{1996} & 1999 & Coats & Hicking Pentecost (Barbour ) & \\
\hline & & 2000 & Coats & Dollfus/Donisthorpe & \\
\hline & & 2001 & Amann & Donisthorpe & \\
\hline & & 2000 & Guetermann & Zwicky & \\
\hline & & 2008 & Amann & Oxley & \\
\hline
\end{tabular}




\begin{tabular}{|c|c|c|c|c|c|}
\hline Cartel & Cartel breakdown & Year of Merger & Firm 1 in Merger & Firm 2 in Merger & CAR of Firm 1 \\
\hline \multirow[t]{4}{*}{ Copper Plumbing Tubes } & \multirow[t]{4}{*}{2001} & 2001 & Outokumpu & Boliden & 0.31565 \\
\hline & & 2002 & $\mathrm{KME}$ & IMI & \\
\hline & & 2002 & Boliden & HME & \\
\hline & & 2003 & Outokumpu & Boliden & 0.04600 \\
\hline Sorbates & 1996 & 2002 & Daicel & Hoechst Nanning & -0.06396 \\
\hline Carbon and Graphite & 1999 & 1999 & Schunk & Hoffmann \& Co & \\
\hline \multirow[t]{2}{*}{ Specialty Graphite } & \multirow[t]{2}{*}{1998} & 2002 & SGL & Tokai & \\
\hline & & 2005 & Carbone Lorraine & $\mathrm{NSCC}$ & \\
\hline \multirow[t]{3}{*}{ Plasterboard } & \multirow[t]{3}{*}{1998} & 2002 & Lafarge & $\mathrm{BPB}$ & \\
\hline & & 2002 & $\mathrm{BPB}$ & Gyproc BeNeLux & \\
\hline & & 2011 & Knauf & Lafarge & \\
\hline Food Flavour Enhancers & 1998 & 2006 & Takeda & Deasang & \\
\hline \multirow[t]{8}{*}{ Dutch Industrial Gases } & \multirow[t]{8}{*}{1997} & 1998 & Air Liquide & $\mathrm{BOC}$ & \\
\hline & & 1999 & Air Liquide & $\mathrm{BOC}$ & 0.02417 \\
\hline & & 2000 & Air Products & AGA & \\
\hline & & 2001 & Air Liquide & Messer & \\
\hline & & 2001 & Air Products & Messer & \\
\hline & & 2002 & Air Liquide & $\mathrm{BOC}$ & 0.03893 \\
\hline & & 2004 & Air Liquide & Messer & -0.05705 \\
\hline & & 2007 & Air Products & $\mathrm{BOC}$ & 0.02641 \\
\hline \multirow[t]{2}{*}{ Austrian Banks } & \multirow[t]{2}{*}{1998} & 1999 & ÖVAG & NÖ Landesbank-Hypothekenbank & \\
\hline & & 2000 & BAWAG & PSK & \\
\hline \multirow[t]{3}{*}{ Vitamins } & \multirow[t]{3}{*}{1994} & 2001 & BASF & Takeda & 0.01056 \\
\hline & & 2001 & Sumitomo & Aventis & -0.07348 \\
\hline & & 2002 & Takeda & Sumitomo & 0.13663 \\
\hline Sodium Gluconate & 1995 & 1995 & Avebe & Akzo & \\
\hline \multirow[t]{2}{*}{ Luxemburg Brewers } & \multirow[t]{2}{*}{2000} & 2000 & Diekirch & Les brasseries réunies (Mousel) & \\
\hline & & 2005 & Nationale-Bofferding & Battin & \\
\hline Graphite Electrodes & 1997 & 2002 & SGL & Tokai & -0.01447 \\
\hline \multirow[t]{2}{*}{ German Banks } & \multirow[t]{2}{*}{1999} & 2002 & Commerzbank & Dresdner Bank & \\
\hline & & 2009 & Commerzbank & Dresdner Bank & -0.13077 \\
\hline Carbonless Paper & 1995 & 1998 & AWA & Bollore & \\
\hline \multirow[t]{7}{*}{ Shipping Agreements } & \multirow[t]{7}{*}{1992} & 1993 & TMM & Tacomar & \\
\hline & & 1994 & Senator & DSR & \\
\hline & & 1996 & $\mathrm{P} \& \mathrm{O}$ & Nedlloyd & \\
\hline & & 1997 & Hanjin & Senator & \\
\hline & & 1999 & Maersk & Land-Sea Service & \\
\hline & & 2003 & MISC & NOL & \\
\hline & & 2005 & Maersk & P\&O Nedlloyd & -0.00850 \\
\hline
\end{tabular}




\begin{tabular}{|c|c|c|c|c|c|}
\hline Cartel & Cartel breakdown & Year of Merger & Firm 1 in Merger & Firm 2 in Merger & CAR of Firm 1 \\
\hline \multirow[t]{3}{*}{ Seamless Steel Tubes } & 1994 & 1997 & Mannesmann & Vallourec & \\
\hline & & 2002 & NKK & Kawasaki & \\
\hline & & 2012 & Nippon Steel & Sumitomo Metal & 0.02344 \\
\hline \multirow[t]{3}{*}{ Pre-insulated pipe } & 1995 & 1997 & Logostor & Pan Isovit & \\
\hline & & 1999 & Logostor & Tarco & \\
\hline & & 2009 & Logostor & Dansk Rorindustri (Starpipe) & \\
\hline British Sugar & 1990 & 2004 & Napier & James Bugett & \\
\hline \multirow[t]{2}{*}{ Alloy Surcharge } & 1995 & 1996 & Krupp & Acciai Speciali Terni & \\
\hline & & 2000 & Krupp Thyssen & Usinor & \\
\hline \multirow[t]{3}{*}{ Ferry Operators } & 1993 & 1996 & $\mathrm{P} \& \mathrm{O}$ & North Sea & \\
\hline & & 1998 & $\mathrm{P} \& \mathrm{O}$ & Stena & \\
\hline & & 2002 & $\mathrm{P} \& \mathrm{O}$ & Stena & \\
\hline \multirow[t]{3}{*}{ Steel Beam } & 1991 & 1997 & Aceralia (Empresa) & Siderúrgica Aristrain & \\
\hline & & 1997 & Arbed & Empresa Nacional & \\
\hline & & 1999 & Thyssen & Krupp Hoesch & \\
\hline \multirow[t]{5}{*}{$\mathrm{PVC}$} & 1987 & 1997 & BASF & Hoechst & \\
\hline & & 1998 & Wacker & Huels & \\
\hline & & 1999 & Solvay & BASF & -0.08594 \\
\hline & & 2000 & BASF & Shell & \\
\hline & & 2002 & Solvay & Montedison (Edison / Ausimont) & 0.03157 \\
\hline \multirow[t]{19}{*}{ Cement } & 1989 & 1990 & Aalborg & Blue Circle & \\
\hline & & 1992 & Italcementi & Ciments Français & \\
\hline & & 1993 & Heidelberger & SA Cimenteries CBR & \\
\hline & & 1993 & Heidelberger & NV-ENCI & \\
\hline & & 1994 & Holderbank & Cedest & \\
\hline & & 1994 & Dyckerhoff & Ciments Luxembourgeois & \\
\hline & & 1995 & Unicem & Italcementi & \\
\hline & & 1995 & EUROC AB & Aker A/S (Norcem) & \\
\hline & & 1996 & Heracles & Halkis & \\
\hline & & 1997 & Alsen-Breitenburg & Nordcement & \\
\hline & & 1999 & Heidelberger & Aker / Scancem & \\
\hline & & 1999 & Fratelli (Buzzi) & Unicem & \\
\hline & & 1999 & Blue Circle & Heracles & \\
\hline & & 2001 & Buzzi & Dyckerhoff & -0.24582 \\
\hline & & 2001 & Lafarge & Blue Circle & \\
\hline & & 2003 & Holcim & Hispacement & 0.12322 \\
\hline & & 2004 & Cementir & Aalborg & \\
\hline & & 2004 & Irish Cement / CRH & SECIL & \\
\hline & & 2007 & Heidelberger & Hanson & -0.03855 \\
\hline \multirow[t]{4}{*}{ Carton Board } & 1991 & 1992 & Mayr-Melnhof & Laakmann Karton GmbH & \\
\hline & & 1994 & Enso-Gutzeit & Tampella Española (Enso) & \\
\hline & & 1998 & Stora & Enso-Gutzeit & \\
\hline & & 2001 & Mayr-Melnhof & Gruber \& Weber GmbH & \\
\hline \multirow[t]{3}{*}{ UK Tractors } & 1984 & 1991 & Fiat & Ford New Holland & \\
\hline & & 1995 & Same-Lamborghini & Deutz-Fahr & \\
\hline & & 1999 & New Holland (Fiat) & Case & -0.04713 \\
\hline
\end{tabular}

